\title{
Recognition of juvenile hawksbills Eretmochelys imbricata through face scale digitization and automated searching
}

\author{
S. G. Dunbar ${ }^{1,2,3,6, *}$, H. E. Ito ${ }^{4}$, K. Bahjri ${ }^{5}$, S. Dehom ${ }^{5}$, L. Salinas ${ }^{6}$ \\ ${ }^{1}$ Marine Research Group, Department of Earth and Biological Sciences, Loma Linda University, Loma Linda, CA 92350, USA \\ ${ }^{2}$ Protective Turtle Ecology Center for Training, Outreach, and Research (ProTECTOR), Colton, CA 92324, USA \\ ${ }^{3}$ Turtle Awareness and Protection Studies Project (TAPS), Oak Ridge, Roatán, Honduras \\ ${ }^{4}$ Department of Biology, Pacific Union College, Angwin, CA 94508, USA \\ ${ }^{5}$ Research Consulting Group, Loma Linda University, Loma Linda, CA 92350, USA \\ ${ }^{6}$ Protective Turtle Ecology Center for Training, Outreach, and Research, Honduras (ProTECTOR Honduras), Tegucigalpa, \\ Honduras
}

\begin{abstract}
Advancements in digital photography have facilitated the use of photo-ID to track individual animals, making this technique of great value for conservation biology. However, the time required to manually match new photographs to those stored in a database is proportional to the size of the database. Therefore, there is need for investigating the potential to automate the searching processes through computerized means. We encountered hawksbill turtles Eretmochelys imbricata $(\mathrm{n}=2)$ that were members of an ongoing study but had lost flipper tags and shell etchings. To identify individuals, we first manually searched photographs of turtles previously captured and released. Manual visual matching of the 2 turtles encountered was successful for $100 \%$ of tested photographs. To investigate automated recognition of turtles in a database, we used the spot recognition program, $\mathrm{I}^{3} \mathrm{~S}$, to digitize scutes on the dorsal and lateral surfaces of the head and to compare spot patterns through the automated system. $I^{3} S$ successfully identified the 2 return turtles as the same turtles identified by the manual visual matching method. To assess the ability of $I^{3} S$ to identify turtles both present in and absent from the database, we blind-tested a series of photographs of turtle heads and faces using both manual visual methods and $\mathrm{I}^{3} \mathrm{~S}$. With $\mathrm{I}^{3} \mathrm{~S}, 84.6 \%$ of the computerized photos were successfully matched with photos in the database, with scores produced ranging from 0.069 to 0.435 . This study showed the potential for using a photo-database for long-term identification of individual turtles, but that the usefulness of a photodatabase depends on the quality of the photos and the flexibility of the computer program used.
\end{abstract}

KEY WORDS: Photo-identification · Automated searching $\cdot$ Sea turtles $\cdot$ Endangered species · Central America

\section{INTRODUCTION}

The ability to recognize individual animals is a key feature in tracking individuals through various life-history stages, usually through capture-markrecapture studies. Effective management of animal populations requires realistic estimates of population numbers. One way to gather information on popula-

${ }^{*}$ Corresponding author: sdunbar@llu.edu tion numbers is through the identification of unique individuals. Thus, the value of an animal increases each time it can be identified and recovered for a specific research program. Artificial tagging of individual animals is common, having been carried out on a wide variety of organisms, such as birds (Verner et al. 2000, Bart et al. 2001, Zimmerman et al. 2009), the Florida manatee Trichechus manatus latirostris

(C) The authors 2014. Open Access under Creative Commons by Attribution Licence. Use, distribution and reproduction are unrestricted. Authors and original publication must be credited. 
(Rathbun et al. 1995), the dugong Dugong dugon (Lanyon et al. 2002), and all species of sea turtles as far back as 1955 (Mrosovsky 1976, Carr et al. 1978, Hughes 1978, Carr 1986).

Sea turtles are among the many species for which long-term data collection is critical for species conservation and management. The majority of sea turtle identification programs utilize tags that consist of metal or plastic bands that are applied to the flipper. However, tag loss is an issue of concern for studies of sea turtle populations. While there is ample evidence that tag losses do occur with increased time between application and recovery (Mrosovsky 1976, Balazs 1982, Mrosovsky \& Shettleworth 1982, Limpus 1992, Reisser et al. 2008), some reports have estimated that annual tag losses may range from $13 \%$ for tags placed in the pre-scale position, to $54 \%$ for tags placed between scales (Reisser et al. 2008), while Mrosovsky \& Shettleworth (1982) reported tag losses as high as $38 \%$ over the first $500 \mathrm{~d}$ after tagging depending on the position of the tag on the front or rear flipper. Hughes (1978) reported that recovery rates of tags greatly improve when the position of tagging on leatherbacks is changed (moved from the front to the hind flipper). In any case, tag losses represent a substantial loss of data if individuals are rendered unidentifiable.

In addition to artificial tags, natural markings, scars, and patterns have been used in photographic indexes in a variety of animals, including long-lived species, such as the African elephant Loxodonta africana (Douglas-Hamilton 1973), the chimpanzee Pan troglodytes (Goodall 1986), the lion Panthera leo (Ogutu et al. 2006), several species of cetaceans (Thompson et al. 2000, Stevick et al. 2001, Frasier et al. 2009), and the sea otter Enhydra lutris (Gilkinson et al. 2007). Speed et al. (2007) used the computer spot recognition program Interactive Individual Identification System $\left(I^{3} S\right)$ to identify spot patterns on the whale shark Rhincodon typus and to test an information criterion algorithm. $\mathrm{I}^{3} \mathrm{~S}$ has also been used for the identification of other organisms. Van Tienhoven et al. (2007) used the program to identify and match underwater photographs of the spotted raggedtooth shark Carcharius taurus, while Speed et al. (2007), Holmberg et al.(2009), and Riley et al. (2010) have all used the program to successfully identify individual whale sharks $R$. typus. This computer system has additionally been used by Caci et al. (2013) to identify individual cerambycid beetles (Rosalia alpine).

A few investigators have recognized the uniqueness of scale patterns in cheloniids and have used photo-identification (ID) techniques to some extent in identifying Dermochelys coriacea (McDonald \& Dutton 1996, Day et al. 2005), Caretta caretta (Schofield et al. 2008, Hays et al. 2010), Chelonia mydas (Reisser et al. 2008, van de Merwe 2009, Lloyd et al. 2012), and Eretmochelys imbricata (Reisser et al. 2008, van de Merwe 2009). In these cases, photo-ID has been used to compare current photographs to previous photographs by reviewing the similarity of characteristic features, usually represented by scale patterns of the head or face. However, efforts to develop systematic techniques for the use of photoID in sea turtle research are still in developmental stages. The effort involved in manually reviewing digital photographs is prohibitive because of the tedious and pain-staking time required, especially when considering large digital databases of hundreds or thousands of photographs. Indeed, a systematic approach to using photo-IDs of sea turtles is generally lacking.

In the current study, we describe the use of a computer-assisted method to automatically search a relatively large database of digital photographs in an attempt to automate the matching process of photoIDs for sea turtles. Our attempt to automate the process is intended to assist manual-visual identification by reducing the time required to perform the task. The ability to rapidly identify sea turtles world-wide through digital imagery holds great potential for expanding our understanding of turtle behaviors, movements, and migrations.

\section{MATERIALS AND METHODS}

Our study site is located at Port Royal on the southeast coast of Roatán, Honduras (Fig. 1). Details of the habitat are provided in Dunbar et al. (2008) and Berube et al. (2012). We retrieved juvenile hawksbill sea turtles Eretmochelys imbricata from local fishers who incidentally captured turtles as bycatch along the reef flats of the area. Since the inception of the study in 2006, we have collected data on each turtle, including curved and straight carapace length and width, and body weight, and then applied Inconel 601-style flipper tags to the right front and right rear flippers (Dunbar 2006, Dunbar et al. 2008). We also etched an identification number into the second left lateral scute of the carapace with a dremel tool. The number was then painted in with White Out ${ }^{\mathrm{TM}}$, covered over with a thin layer of DAP Kwik Seal ${ }^{\mathrm{TM}}$ clear caulking, and allowed to dry in air. In addition, whenever turtles were captured we regularly took digital photographs of the dorsal surface of the head 
and both right and left sides of the face of each turtle. These photographs were taken at a distance of approximately $1 \pm 0.03 \mathrm{~m}$ (dorsal) and $0.03 \pm 0.01 \mathrm{~m}$ (lateral) away from each subject while turtles were out of water. Photographs of each individual were kept in individual computer folders for each turtle.

\section{Manual-visual analysis of turtle returns}

In July 2010, we received from local fishers 2 turtles that we recognized as members of the ongoing study by the faded etchings in the left lateral scutes and perforations left in the front and rear right flippers from the intentional removal of the tags. Although clearly part of the study, these turtles were unidentifiable from previous tags. We then took new digital photographs and manually searched our database of photographs to identify potential matches of old photographs with new ones. As with our previous method, these new photographs were likewise taken at a distance of approximately $1 \pm 0.03 \mathrm{~m}$ (dorsal) and $0.03 \pm$ $0.01 \mathrm{~m}$ (lateral) away from each subject while turtles were out of water. In order to quantify the effort per identified unit (EIU), we used the formula:

$$
\mathrm{EIU}=t_{\mathrm{s}}(N)+t_{\mathrm{v}}(\mathrm{n})+t_{\mathrm{i}}
$$

where $t_{\mathrm{s}}$ is the time ( $\mathrm{min}$ ) required to check 1 image for apparent matches from all images $(N)$ in the data-

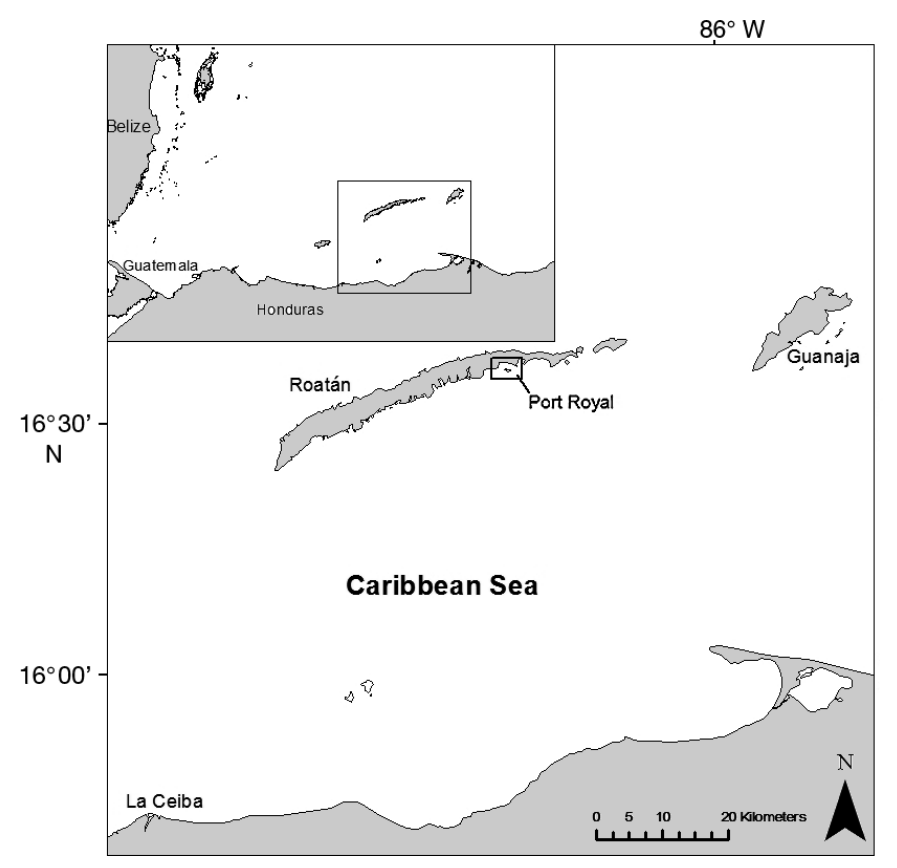

Fig. 1. Map of the study site on Roatán, among the Bay Islands of Honduras. Inset: north coast of Honduras and the Bay Islands base, $t_{\mathrm{v}}$ is the time (min) required to verify 1 match from $\mathrm{n}$ apparent matches, and $t_{\mathrm{i}}$ is the time (min) to initialize and finalize the search procedure.

\section{Manual-visual analysis versus computer-assisted analysis of turtle returns}

We then sought to digitize a standard set of scute patterns in an effort to automate the search system and to verify the results by manual inspection. Initially, we sought to digitize the scute pattern by digitally tracing the lines of a standard set of head and face scutes. However, we were unable to locate a computer program that would scan and match polygons from a photographic database. We used the program $I^{3} \mathrm{~S}$ (available from www.reijns.com/i3s/) (den Hartog \& Reijns 2007, Speed et al. 2007, van Tienhoven et al. 2007). While there are currently 4 versions of the software available ('Classic', 'Spot', 'Contour', and 'Pattern'), we used $\mathrm{I}^{3} \mathrm{~S}$ Classic, the most recent version available at the time of the study, to digitize the head- and face-scale patterns of recaptured turtles, and compared these digitized files. ${ }^{3} \mathrm{~S}$ was built to assist photo-ID by decreasing the number of photographs used for the final manual photo-ID. Using this program, head and face scales of each individual turtle were spotted by clicking on the intersections between scales. A standard series of points on the dorsal view of the turtle head were marked with a digital spot where the angle of the scale line changes directions, making 17 points (Fig. 2). Three additional control points for the dorsal view were placed at the top of the prefrontal scale, and on the lateral parietal scales for a total of 20 points (Fig. 2). For lateral views, a standard could not be made, because each turtle has a unique set of lateral scutes differing in number and shape. Thus, for the lateral views, instead of a standard set number of points, as many points as possible were placed at the vertices of 5 standard scutes. The points were placed around each vertex of the 3 post-ocular scales and the 2 most superior scales that follow the post-ocular scale, creating a variation of spots depending on the scale patterns of unique individuals. For instance, in Fig. 3A the photograph was spotted with 18 spots unique to this individual, whereas in Fig. 3B the photograph was spotted with 20 spots unique to this turtle. Only vertices created by intersections of scales or between a scale and the beak were digitized. Despite these variations in spotting patterns, the selection method for these points is univocal; therefore, a given scale pattern may only yield 1 spot pattern. $\mathrm{I}^{3} \mathrm{~S}$ takes into consideration how 


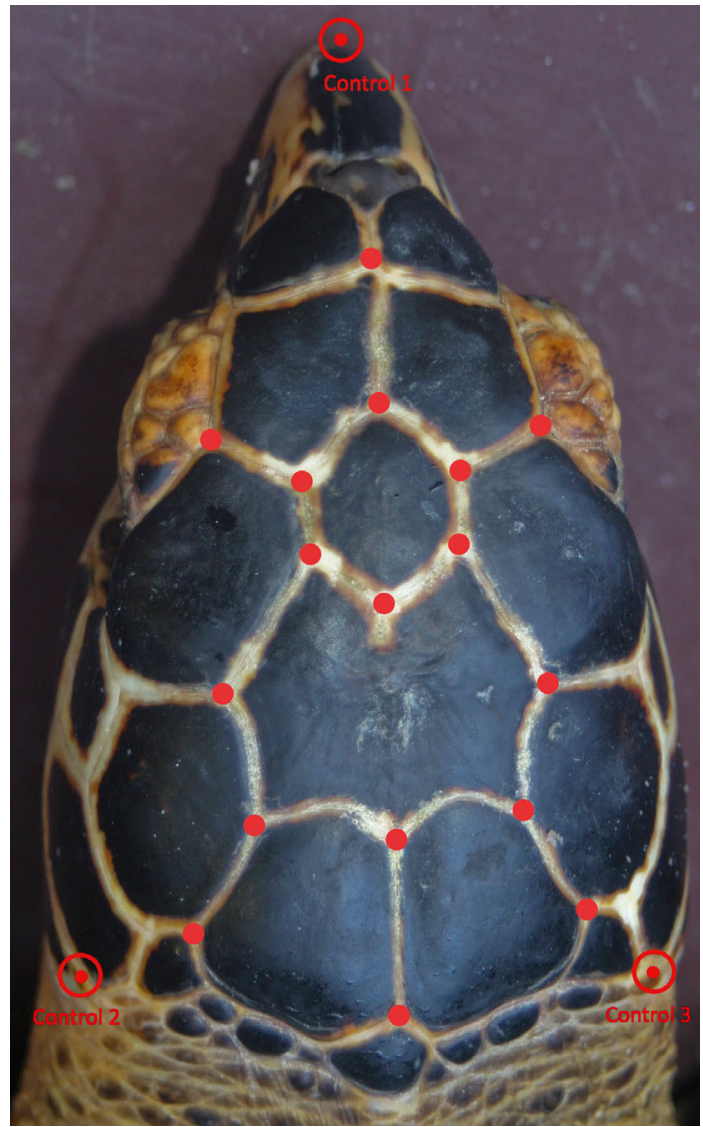

Fig. 2. Eretmochelys imbricata. The 17 standardized points for the dorsal view of the turtle head, along with the 3 control points used for the dorsal view of the turtle head when digitizing each turtle photograph for the database and test photographs. The first control point is placed on the top of the prefrontal scale, the second on the left lateral parietal scale, and the third on the right lateral parietal scale

many spots there are. Thus, the more variation in pattern and number of points, the easier it is for a correct match to be identified. If an unknown turtle is spotted with 15 points, the program tends to ignore individuals with more or fewer points. Since the location of points to be placed is set by the number of vertices around the chosen scales, new photographs of the unknown individual will be digitized with the same number of points as the photographs already present in the database, with the number of vertices unique to each individual. Control points for the lateral view were placed at the most superior point of the eye, the tip of the beak, and the farthest posterior point of the mouth line (Fig. 3A,B).

Two hundred turtles (approximately 600 photographs) were marked with spots, and the database was then used to test the ability of $\mathrm{I}^{3} \mathrm{~S}$ to correctly identify those turtles.

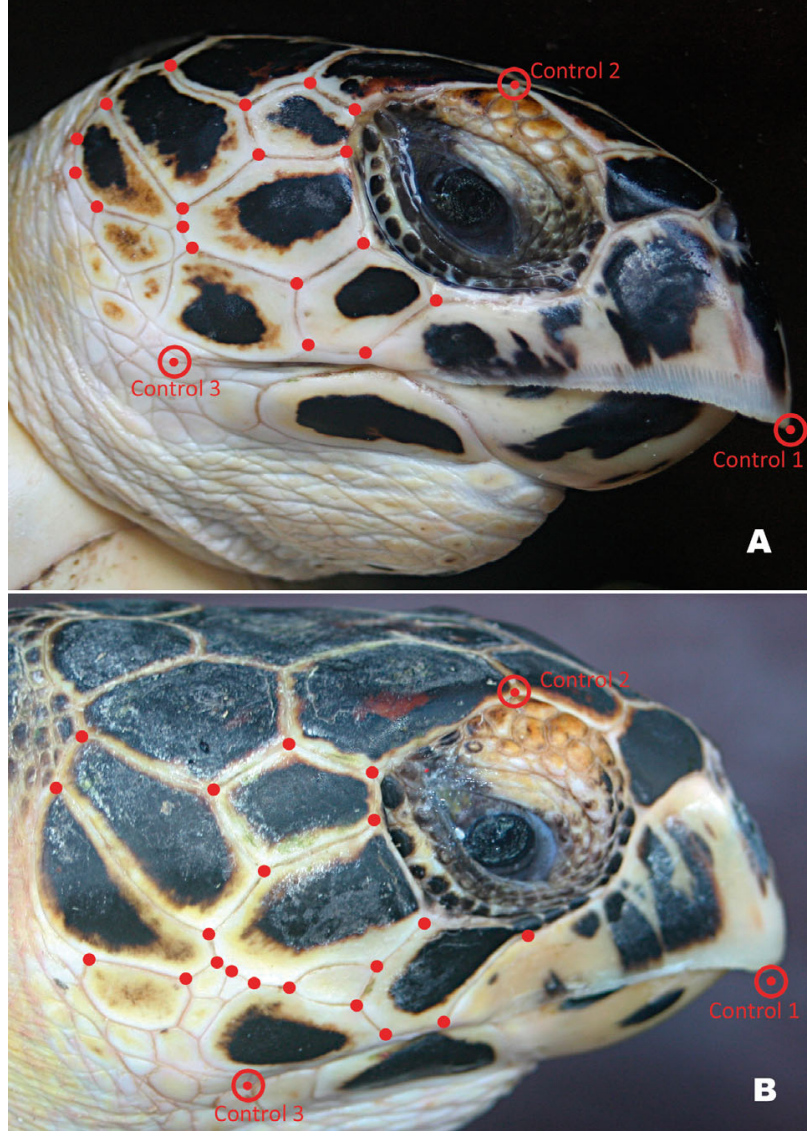

Fig. 3. Eretmochelys imbricata. Examples of digital points used for the lateral view of the turtle head, with the 3 control points. The first point was located at the tip of the beak; the second, at the most superior point of the eye; and the third, at the farthest edge of the tympanic scales. (For details of analysis see 'Materials and methods'.) Shown are turtles (A) with 18 points, and (B) with 20 points

\section{Manual-visual versus computer-assisted testing}

Test photographs of 28 dorsal and lateral views of turtles were randomly chosen from the compilation of photographs on file (different from those spotted [digitized] in the database), or randomly selected from the Internet. We tested photographs through a 1 -way blind test by having one author choose the test photographs from the database and one of the other authors run the test through manual and automated $\left(\mathrm{I}^{3} \mathrm{~S}\right)$ searching. In this way the person who supplied the photographs always knew the correct identification of the turtle photographs.

These photographs were then spotted and analytically compared by $\mathrm{I}^{3} \mathrm{~S}$ to test the effectiveness of this comparison method. To compare potential matches, the program uses the following distance metric to determine the closeness of the matched spots: 


$$
\frac{\sum_{i=1}^{n} \operatorname{dist}(i)}{n^{2}}
$$

where $n$ is the number of spot pairs, and dist(i) is the distance between each spot pair.

If 2 photographs have a large number of matched spot pairs, a low score will be generated due to the short distance between each spot and its match. A score of $<1$ is a strong match. We then visually compared the 2 photographs (test photograph and matched result). The array of spots can be put together so that visual comparison of the spot matches can be seen (Fig. 4). The program accepts 2 spots as matches if the distance of the spot to an alternate spot is at least double the distance of the current match.

The head- and face-scale patterns of 28 turtles were manually and visually compared to those of turtles in the database. Of the 28 tests performed using both

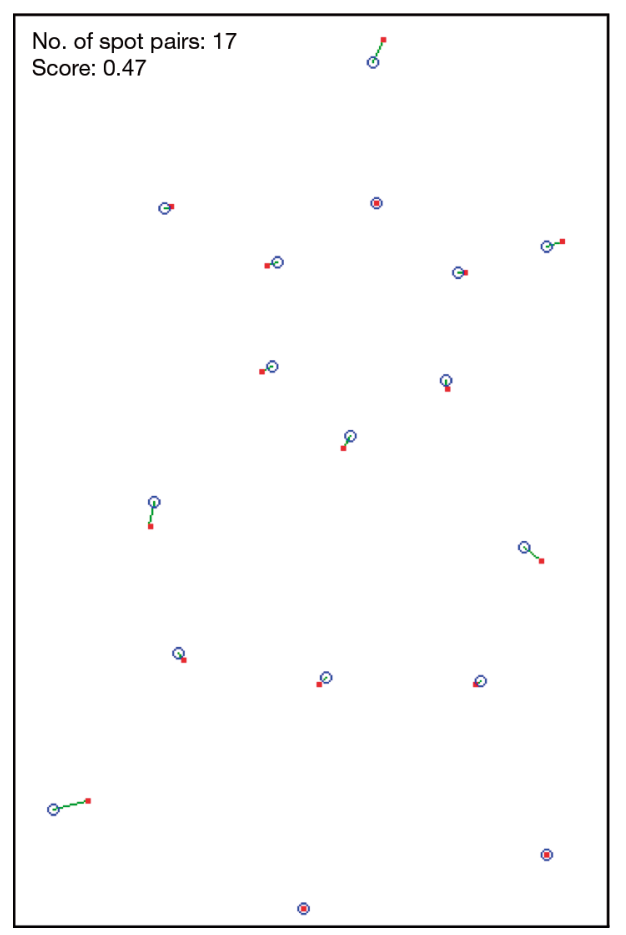

Fig. 4. Eretmochelys imbricata. The spot cloud which compares the unknown test individual with a possible match in the database (found individual). This one compares the match between the dorsal view photographs of the same individual (TIN \#059) from 2007 and 2010. The red dot array shows the digitized spots of the 2007 photograph, while the blue circles denote those of the 2010 photograph. The lines in between some dots and circles mean that the distances between the spots are close enough to be considered matching. The score of 0.47 , where any score $<1$ denotes a strong match, means that the $\mathrm{I}^{3} \mathrm{~S}$ program correctly matched these photographs of the same individual manual-visual analysis and computer-assisted analysis, 15 of the test animals did not already have photographs in the database. Photographs of these test animals were either photographs of the dorsal surface of hawksbill heads randomly selected from the Internet $(\mathrm{n}=3)$, or were photographs of new project turtles that had not previously been captured at the project site $(n=12)$. These tests were analyzed independently of the test photographs of turtles that were already in the photo-database.

The proportion of agreement of visual comparisons was compared with computerized matching results presented by I ${ }^{3} \mathrm{~S}$.

\section{Statistical analyses}

All statistical analyses were performed using the Statistical Package for the Social Sciences (SPSS) Version 20.0 (IBM 2011). Descriptive statistics are given as counts of turtles identified for both the computer-aided matching as well as for visual matching. Kappa statistics were used to measure the agreement between the 2 methods of measurements. In addition, sensitivity was used to assess the validity of visual and computerized methods.

We used an independent sample $t$-test to compare the means of match scores between test photographs of turtles already in the database and test photographs of turtles that were new to the database. Of the 13 test turtles with previous photographs in the database, we excluded 2 of these (Test Turtles 2 and 4 ) as outliers from the $\mathrm{I}^{3} \mathrm{~S}$ mean match score because both the database and test photographs were very small, of sufficiently poor quality and resolution that consistent digital spotting could not clearly be accomplished, and before and after photographs were taken at drastically different angles.

Significance level was set at $\alpha=0.05$.

\section{RESULTS}

\section{Manual-visual analysis of turtle returns}

After manually comparing new head- and facescale photographs of Eretmochelys imbricata with several hundred photographs already in the project database, we were able to positively identify both of the turtles returned to the study in Roatán through manual-visual analysis of unique markings and scars on the dorsal surface of the head (Fig. S1 in the Supplement at www.int-res.com/articles/suppl/n026p137 
Table 1. Details of hawksbill turtles Eretmochelys imbricata released in 2007 that returned to the study site in Roatán in 2010. Both turtles were identified as juveniles, due to size, and were captured, released, and recaptured in the same area of Port Royal. Dates are mm/dd/yy. $\mathrm{CCL}_{\text {min }}$ : minimum curved carapace length

\begin{tabular}{|lccccccc|}
\hline $\begin{array}{l}\text { Database } \\
\text { turtle ID no. }\end{array}$ & $\begin{array}{c}\text { Date } \\
\text { captured }\end{array}$ & $\begin{array}{c}\text { Capture } \\
\text { CCL }_{\text {min }}(\mathrm{cm})\end{array}$ & $\begin{array}{c}\text { Date } \\
\text { released }\end{array}$ & $\begin{array}{c}\text { Release } \\
\text { weight }(\mathrm{kg})\end{array}$ & $\begin{array}{c}\text { Date } \\
\text { recaptured }\end{array}$ & $\begin{array}{c}\text { Recapture } \\
\text { CCL }_{\text {min }}(\mathrm{cm})\end{array}$ & $\begin{array}{c}\text { Release } \\
\text { weight }(\mathrm{kg})\end{array}$ \\
\hline TIN 050-07 & $6 / 22 / 07$ & 23.8 & $9 / 03 / 07$ & 1.2 & $7 / 05 / 10$ & 46.6 & 8.6 \\
TIN 059-07 & $11 / 15 / 07$ & 26.6 & $11 / 15 / 07$ & 2.3 & $7 / 01 / 10$ & 41.6 & 8.5 \\
\hline
\end{tabular}

_supp.pdf) and other areas of the body. However, this process required approximately $180 \mathrm{~min}$ of manually searching the photographic database. The resultant time to identify individuals was 90 min for each turtle. Details of release dates, morphometrics, and rerelease dates are provided in Table 1, while photos used for comparisons are provided in Fig. S2 in the Supplement.

\section{Manual-visual analysis versus computer-assisted analysis of turtle returns}

In the case of the 2 turtles that returned to the study site in Roatán, $\mathrm{I}^{3} \mathrm{~S}$ provided a list of 50 possible matches to new photographs from a pool of approximately 600 photographs already in the database, with the most likely match (smallest score) presented at the top of the list.

In the results generated by the program, red dots represented the unknown test turtle's spots, while blue circles represented the spots of the matching individual. Green relation lines between spots represent matching spot pairs (Fig. 4). The process of selecting several potential matches from all digital photographs took only a matter of 0.5 min using $\mathrm{I}^{3} \mathrm{~S}$. However, these potential matches through $\mathrm{I}^{3} \mathrm{~S}$ required further analyses using manual-visual techniques. Still, the combined process of computerassisted searching and manual-visual analysis of potential matches resulted in an identification time of only $8 \mathrm{~min}$. Utilizing $\mathrm{I}^{3} \mathrm{~S}$ reduced the time required for identification through manual searching alone by $82 \mathrm{~min}$.
Table 2. Identification numbers selected as matches by both the manual-visual and computer-assisted $\left(\mathrm{I}^{3} \mathrm{~S}\right)$ methods for blind tests of hawksbill turtles Eretmochelys imbricata whose photographs were already in the photographic database. The $\mathrm{I}^{3} \mathrm{~S}$ match score, derived from the distance matrix for each computer match, is provided in the last column. Rows in bold print are false positives by the $I^{3} \mathrm{~S}$ method. Rows in italic print are false positives by the manualvisual method

\begin{tabular}{|c|c|c|c|c|}
\hline $\begin{array}{l}\text { Test } \\
\text { turtle }\end{array}$ & $\begin{array}{l}\text { Database } \\
\text { turtle ID no. }\end{array}$ & $\begin{array}{l}\text { Manual-visual } \\
\text { method }\end{array}$ & $\mathrm{I}^{3} \mathrm{~S}$ method & $\begin{array}{l}\mathrm{I}^{3} \mathrm{~S} \text { match } \\
\text { score }\end{array}$ \\
\hline 1 & TIN 075-08 & TIN 075-08 & TIN 075-08 & 0.164 \\
\hline 2 & TIN 102-10 & TIN 102-10 & TIN 091-10 & 2.076 \\
\hline 3 & TIN 037-06 & TIN 037-06 & TIN 037-06 & 0.101 \\
\hline 4 & TIN 045-06 & TIN 045-06 & TIN 039-06 & 3.983 \\
\hline 5 & TIN 095-09 & TIN 095-09 & TIN 095-09 & 0.069 \\
\hline 6 & TIN 044-06 & TIN 044-06 & TIN 044-06 & 0.191 \\
\hline 7 & TIN 048-07 & TIN 055-07 & TIN 048-07 & 0.347 \\
\hline 9 & TIN 083-08 & TIN 083-08 & TIN 083-08 & 0.293 \\
\hline 10 & TIN 048-07 & TIN 048-07 & TIN 048-07 & 0.178 \\
\hline 11 & TIN 054-07 & TIN 054-07 & TIN 054-07 & 0.155 \\
\hline 13 & TIN 077-08 & TIN 077-08 & TIN 077-08 & 0.264 \\
\hline 14 & TIN 068-08 & TIN 068-08 & TIN 068-08 & 0.404 \\
\hline 16 & TIN 101-10 & TIN 101-10 & TIN 101-10 & 0.435 \\
\hline \multicolumn{2}{|c|}{ Positive matches } & $\begin{array}{c}92.3 \% \\
(12 \text { of } 13)\end{array}$ & $\begin{array}{c}84.6 \% \\
(11 \text { of } 13)\end{array}$ & $\begin{array}{l}\text { Avg. score } \\
(0.236)\end{array}$ \\
\hline
\end{tabular}

\section{Manual-visual versus computer- assisted testing}

Percent matches from both computer-aided matching and human visual matching of test turtles are presented in Table 2 for all 13 new turtle photos in the database. When identified by the $\mathrm{I}^{3} \mathrm{~S}$ computer-aided method, measures of sensitivity of these tests showed $84.6 \%$ of turtles were correctly matched, while visual matching yielded $92.3 \%$. The average match score provided by $\mathrm{I}^{3} \mathrm{~S}$ for turtles found in the database was 0.236 , with a range of 0.069 to 0.435 .

Of the turtles tested that were not previously in the photo-database $(\mathrm{n}=$ 15), we found that $86.7 \%$ were correctly identified as having 'no match' in the database, and $13.3 \%$ (2 of 15) were misidentified as having a match in the database (false positives) by the manual-visual method (Table 3, 
Table 3. Identification numbers of potential matches for photographs of hawksbill turtles Eretmochelys imbricata not previously in the project database (NID) and tested by both manual-visual and computer-assisted $\left(\mathrm{I}^{3} \mathrm{~S}\right)$ methods. The $\mathrm{I}^{3} \mathrm{~S}$ match score, derived from the distance matrix for each computer match, is provided in the last column. Rows in italic print are false positives by the manual-visual method

\begin{tabular}{|lcccc|}
\hline $\begin{array}{l}\text { Test } \\
\text { Turtle }\end{array}$ & $\begin{array}{c}\text { Database } \\
\text { turtle ID no. }\end{array}$ & $\begin{array}{c}\text { Manual-visual } \\
\text { method }\end{array}$ & I'S method & $\begin{array}{c}\text { I } \text { S match } \\
\text { score }\end{array}$ \\
\hline 8 & NID & No match & TIN 053-07 & 1.505 \\
12 & NID & No match & TIN 075-08 & 0.268 \\
15 & NID & No match & TIN 103-10 & 0.321 \\
17 & TIN 114-11 & No match & TIN 076-08 & 1.478 \\
18 & TIN 115-11 & No match & TIN 084-08 & 0.675 \\
19 & TIN 116-11 & No match & TIN 059-07 & 0.956 \\
20 & TIN 117-11 & No match & TIN 091-09 & 0.726 \\
21 & TIN 118-11 & No match & TIN 054-07 & 1.345 \\
22 & TIN 119-11 & No match & TIN 061-07 & 0.903 \\
23 & TIN 120-11 & TIN 075-08 & TIN 028-06 & 0.417 \\
24 & TIN 121-11 & No match & TIN 096-09 & 0.690 \\
25 & TIN 122-11 & TIN 081-08 & TIN 041-06 & 0.825 \\
26 & TIN 123-11 & No match & TIN 024-06 & 0.806 \\
27 & TIN 124-11 & No match & TIN 084-08 & 0.722 \\
28 & TIN 125-11 & No match & TIN 108-10 & 0.633 \\
Positive & matches & 86.7\% & $0 \%$ & Avg. Score \\
& & (13 of 15) & $(0$ of 15) & $(0.818)$ \\
\hline
\end{tabular}

Fig. S3 in the Supplement). However, when the $\mathrm{I}^{3} \mathrm{~S}$ program was presented with the same 15 photographs, all resulting matches were false positives (Table 3).

There was a significantly higher mean $\mathrm{I}^{3} \mathrm{~S}$ test score $\left(t_{18}=5.57, \mathrm{p}<0.001\right)$ for matches of photographs of animals that were not in the database $(0.818 \pm 0.379)$ versus $I^{3} \mathrm{~S}$ test scores for animals that were in the database $(0.236 \pm 0.121)$.

\section{DISCUSSION}

We have provided results of tests utilizing computer-assisted searching techniques for sea turtle head and face recognition. The current study adds sea turtles to the list of animals for which $\mathrm{I}^{3} \mathrm{~S}$ can be successfully utilized to reduce the amount of time used to manually search photo-databases. In the current study, we used photographs taken at relatively consistent distances away from our turtles (Eretmochelys imbricata) out of water. This method, therefore, has the potential for improving the success rate of the computer program to detect subject matches. Nevertheless, we provide evidence that computerassisted, automated searching of photographic databases is possible, although at this stage it may still require the specificity and selectivity provided by manual-visual analysis of potential matches selected by the program $I^{3} \mathrm{~S}$. We found that matching by $\mathrm{I}^{3} \mathrm{~S}$ could be maximized if photographs were taken at right angles to the plane of the turtle and from approximately the same distance. However, this is likely to be done consistently only in a context where turtles are above water, as in the current study, and less likely to be possible while diving or snorkeling. While removing turtles from the water may be considered 'non-natural,' nesting turtles do provide unique opportunities to collect specific photographs in natural, but above-water situations. Still, the ultimate goal of photoidentification is to minimize disturbance and capture photographs of the animal in its natural habitat for subsequent identification. While other studies have successfully utilized in-water digital photography to identify recaptured sea turtles (McDonald \& Dutton 1996, Reisser et al. 2008, Schofield et al. 2008, Hays et al. 2010, Lloyd et al. 2012), few other reports have been published on efforts to utilize computerized techniques to automate the process of searching large photographic databases (Buonantony 2008, Pauwels et al. 2008, Jean et al. 2010, Lloyd et al. 2012).

In sea turtle research, there is need to repeatedly identify the same individuals over time, providing long-term and potentially valuable information on individual habits, biology, and life history. This ability is sometimes hampered by the loss of external tags (Balazs 1982, Mrosovsky \& Shettleworth 1982, Reisser et al. 2008), which may be lost, torn off, or intentionally removed, and the loss of natural, intentional, or injury markings, which may grow out or heal over time (Hendrickson \& Hendrickson 1981, Bentivegna et al. 1993, Troëng et al. 2006). Advances in digital photography have provided the means of capturing high-resolution images, both on land and under water. In some cases, natural markings have been successfully used to assess various life-history processes in sea turtles. For example, Schofield et al. $(2008,2009)$ and Hays et al. (2010) used underwater photographs to accurately identify individual scale patterns of adult loggerhead sea turtles Caretta caretta and to analyze spatial use and breeding periodicity of male and female loggerheads off the coast of Greece. The capacity to manually match new pho- 
tographs of individuals with previous photographs of the same individual is highly useful, although the time required to accomplish such a task is proportional to the number of photographs in a project database (van Tienhoven et al. 2007). Still, the ability to match photographs from a single individual at different times and locations can provide information that is, at present, difficult to gather remotely. For instance, while analytical programs, such as MARK (Gary White; Colorado State University), are able to analyze capture-mark-recapture data at a single location, this type of analysis provides no information regarding where the animal has moved in the intervening days, months, or years.

Advances in satellite telemetry have resulted in the ability to remotely track animals great distances over long periods of time (Hays et al. 2001, Horrocks et al. 2001, Coyne \& Godley 2005, Troëng et al. 2005, Blumenthal et al. 2006, Godley et al. 2008, van Dam et al. 2008). However, aside from time-depth recordings (van Dam \& Diez 1997, Houghton et al. 2000, Schofield et al. 2007), satellite data are unable to provide details of the exact locations and activities of the animals in the locations where transmissions originate. On the other hand, digital photography has become a tool used by divers, snorkelers, and individuals attending nesting beaches around the world. With the ability to rapidly upload and retrieve digital images from around the world, there is great potential for photographically tracking animals in good detail.

\section{Program limitations and perspectives}

While $\mathrm{I}^{3} \mathrm{~S}$ provides an excellent means to automate rapid searches of photographic databases, reducing the manual and visual time required to identify individuals, it likewise has some limitations in its application for consistent identifications of turtles as a standalone automated search system. Our results suggest that this program has some limitations in specificity and selectivity, which, on its own, may not consistently result in high levels of confidence in resulting photographic matches. This is in contrast to manualvisual matches made by humans, who, instead of using similarities in intersection spots, are able to distinguish turtle heads and faces using unique, yet subtle similarities and differences present in features such as marks, scars, and scale shapes. Our photographs were taken above water, representing nonnatural conditions. Photographs taken in natural underwater conditions present the additional challenges of ripple patterns, distortions, and light varia- tions, which may involve further challenges for automating this and other computer photographic searching and matching processes.

Another limitation of the program is that it does not currently have a setting in which the computer presents a result of 'no match' when the distance matrix calculation goes above a specified cutoff value. The result of this is that the program makes selections of matching photographs that are, to the human eye, clearly mismatched. Thus, the program provides false positives when there is no matching individual in the database.

A final and fairly important limitation is the apparent imprecision of the program to distinguish between the same series of digital spots on the same turtle when photographs are taken from slightly different angles or distances. Thus, photographs used with this program must be repeatedly taken at right angles to the surface of the animal (or at least in a very similar orientation) and from approximately the same distance away. This, in some ways, limits the ability of the program to make consistently repeatable identifications when using photographs from sources outside of a specific project methodology. However, this problem is not unique to $\mathrm{I}^{3} \mathrm{~S}$ (Arzoumanian et al. 2005) and is likely to be encountered in the use of any current computer-assisted, automated photo-ID system.

Computer-assisted photographic analysis appears, at this stage, to be limited mainly by the development of programs that are both flexible enough and specific enough to correctly identify subjects irrespective of photograph angle, lighting, and clarity. However, we found $\mathrm{I}^{3} \mathrm{~S}$ to be extremely useful in reducing the time required for searching photographs, and believe that, with further developments of this userfriendly program in the areas of specificity and reliability while being able to utilize digital images from a wide range of views and with varying quality, this system may have far-reaching implications for identifying turtles on a global scale, significantly increasing our ability to track turtles throughout different life-history stages.

Acknowledgements. We are grateful to the Reef House Resort in Roatán for their continuing support of the Turtle Awareness and Protection Studies (TAPS) program, and especially to Larry and Carol Stevenson, and Ashley and Barry Kenewell for their involvement in the research and conservation of sea turtles in Honduras. Research Permit SAG362012 was provided by the Secretary of Agriculture and Ranching (SAG) and the Department of Fisheries (DIGEPESCA), Honduras. Thanks to Tyler dos Santos, who assisted in preparing some of the figures and tables, and Dustin Baumbach for producing the map illustration. We are grateful to the students of the Marine Research Group (LLU) 
for a thoughtful and critical review of the manuscript and many helpful comments. Three anonymous reviewers provided helpful comments that enhanced the clarity and impact of the manuscript. Monica Ferris has continued to provide helpful assistance with our USFWS CITES import permits. This research was carried out in compliance with both national and international law, and was approved by the Loma Linda University Institutional Animal Care and Use Committee protocol IACUC\#8120038. This is Contribution Number 22 of the Marine Research Group (LLU), and Contribution Number 9 of ProTECTOR.

\section{LITERATURE CITED}

Arzoumanian Z, Holmberg J, Norman B (2005) An astronomical pattern-matching algorithm for computer-aided identification of whale sharks Rhincodon typus. J Appl Ecol 42:999-1011

Balazs GH (1982) Factors affecting the retention of metal tags on sea turtles. Mar Turtle Newsl 20:11-14

Bart J, Battaglia D, Senner N (2001) Effects of color bands on semipalmated sandpipers banded at hatch. J Field Ornithol 72:521-526

Bentivegna F, Cirino P, Toscano A (1993) Care and treatment of loggerhead sea turtles from the Gulf of Naples, Italy. Mar Turtle Newsl 61:6-7

> Berube MD, Dunbar SG, Rützler K, Hayes WK (2012) Home range and foraging ecology of juvenile hawksbill sea turtles (Eretmochelys imbricata) on inshore reefs of Honduras. Chelonian Conserv Biol 11:33-43

Blumenthal JM, Solomon JL, Bell CD, Austin TJ and others (2006) Satellite tracking highlights the need for international cooperation in marine turtle management. Endang Species Res 2:51-61

Buonantony DM (2008) An analysis of utilizing the leatherback's pineal spot for photo-identification. MS thesis, Duke University, Durham, NC

Caci G, Biscaccianti A, Cistrone L, Bosso L, Garonna A, Russo D (2013) Spotting the right spot: computer-aided individual identification of the threatened cerambycid beetle Rosalia alpina. J Insect Conserv 17:787-795

Carr AF (1986) The sea turtle: so excellent a fish. University of Texas Press, Austin, TX

Carr A, Carr MH, Meylan AB (1978) The ecology and migrations of sea turtles. 7 . The west Caribbean green turtle colony. Bull Am Mus Nat Hist 162:1-46

> Coyne MS, Godley BJ (2005) Satellite tracking and analysis tool (STAT): an integrated system for archiving, analyzing and mapping animal tracking data. Mar Ecol Prog Ser 301:1-7

> Day RD, Christopher SJ, Becker PR, Whitaker DW (2005) Monitoring mercury in the loggerhead sea turtle, Caretta caretta. Environ Sci Technol 39:437-446

den Hartog J, Reijns R (2007) ${ }^{3}$ S manual interactive individual identification system, Version 2. www.reijns.com/ about/13S_Classic.html (accessed 18 Oct 2010)

Douglas-Hamilton I (1973) On the ecology and behavior of the Lake Manyara elephants. East Afr Wildl J 11:401-403

Dunbar SG (2006) Preliminary report on activities under interim permits \# DGPA/005/2006 and DGPA/245/2006 by the Turtle Awareness and Protection Studies (TAPS) Group under the Protective Turtle Ecology Center for Training, Outreach, and Research (ProTECTOR). Loma Linda University, Loma Linda
Dunbar SG, Salinas L, Stevenson L (2008) In-water observations of recently-released juvenile hawksbills (Eretmochelys imbricata). Mar Turtle Newsl 121:5-9

Frasier TR, Hamilton PK, Brown MW, Kraus SD, White BN (2009) Sources and rates of errors in methods of individual identification for North Atlantic right whales. J Mammal 90:1246-1255

Gilkinson AK, Pearson HC, Weltz F, Davis RW (2007) Photoidentification of sea otters using nose scars. J Wildl Manag 71:2045-2051

Godley BJ, Blumenthal JM, Broderick AC, Coyne MS, Godfrey MH, Hawkes LA, Witt MJ (2008) Satellite tracking of sea turtles: Where have we been and where do we go next? Endang Species Res 4:3-22

Goodall J (1986) The chimpanzees of Gombe: patterns of behavior. The Belknap Press of Harvard University Press, Boston, MA

Hays GC, Akesson S, Godley BJ, Luschi P, Santidrian P (2001) The implications of location accuracy for the interpretation of satellite-tracking data. Anim Behav 61:1035-1040

Hays GC, Fossette S, Katselidis KA, Schofield G, Gravenor MB (2010) Breeding periodicity for male sea turtles, operational sex ratios, and implications in the face of climate change. Conserv Biol 24:1636-1643

Hendrickson LP, Hendrickson JR (1981) A new method for marking sea turtles. Mar Turtle Newsl 19:6-7

> Holmberg J, Norman B, Arzoumanian Z (2009) Estimating population size, structure, and residency time for whale sharks Rhincodon typus through collaborative photoidentification. Endang Species Res 7:39-53

Horrocks JA, Vermeer LA, Krueger B, Coyne M, Schroeder BA, Balazs GH (2001) Migration routes and destination characteristics of post-nesting hawksbill turtles satellitetracked from Barbados, West Indies. Chelonian Conserv Biol 4:107-114

Houghton JDR, Woolmer A, Hays GC (2000) Sea turtle diving and foraging behaviour around the Greek Island of Kefalonia. J Mar Biol Assoc UK 80:761-762

Hughes G (1978) Tagging leatherbacks. Mar Turtle Newsl 6:4

Jean C, Ciccione S, Talma E, Ballorain K, Bourjea J (2010) Photo-identification method for green and hawksbill turtles - first results from Reunion. Ind Ocean Turtle Newsl 11:8-13

Lanyon JM, Sneath HL, Kirkwood JM, Slade RW (2002) Establishing a mark-recapture program for dugongs in Moreton Bay, South-East Queensland. Aust Mammal 24: 51-56

Limpus CJ (1992) The hawksbill turtle, Eretmochelys inbricata, in Queensland: population structure within a southern Great Barrier Reef feeding ground. Wildl Res 19: 489-505

Lloyd JR, Maldanado MA, Stafford R (2012) Methods of developing user-friendly keys to identify green sea turtles (Chelonia mydas L.) from photographs. Int J Zool 2012, doi:10.1155/2012/317568

McDonald DL, Dutton PH (1996) Use of PIT tags and photoidentification to revise remigration estimates of leatherback turtles (Dermochelys coriacea) nesting in St. Croix, U.S. Virgin Islands, 1979-1995. Chelonian Conserv Biol 2:148-152

Mrosovsky N (1976) The tag loss problem. Mar Turtle Newsl $1: 3-4$

Mrosovsky N, Shettleworth JS (1982) What double tagging studies can tell us. Mar Turtle Newsl 22:11-15

Ogutu JO, Piepho HP, Dublin HT, Reid RS, Bhola N (2006) 
Application of mark-recapture methods to lions: satisfying assumptions by using covariates to explain heterogeneity. Book 269. Blackwell Publishing, London

Pauwels EJ, de Zeeuw PM, Buonantony DM (2008) Leatherbacks matching by automated image recognition. In: Perner P (ed) Advances in data mining. Medical applications, e-commerce, marketing, and theoretical aspects. Proc 8th Industrial Conference, (ICDM) 2008, Leipzig, Germany, July 16-18, 2008. LNCS 5077, Springer, Berlin, p 417-425

Rathbun GB, Reid JP, Bonde RK, Powell JA (1995) Reproduction in free-ranging Florida manatees. In: O'Shea TJ, Ackerman BB, Percival HF (eds) Population biology of the Florida manatee, Technology Report No. 1. US Department of the Interior, National Biological Service, Washington, DC, p 135-156

Reisser J, Proietti M, Kinas P, Sazima I (2008) Photographic identification of sea turtles: method description and validation, with an estimation of tag loss. Endang Species Res 5:73-82

Riley MJ, Hale MS, Harman A, Rees RG (2010) Analysis of whale shark Rhincodon typus aggregations near South Ari Atoll, Maldives Archipelago. Aquat Biol 8:145-150

Schofield G, Bishop CM, MacLean G, Brown P and others (2007) Novel GPS tracking of sea turtles as a tool for conservation management. J Exp Mar Biol Ecol 347:58-68

Schofield G, Katselidis KA, Dimopoulos P, Pantis JD (2008) Investigating the viability of photo-identification as an objective tool to study endangered sea turtle populations. J Exp Mar Biol Ecol 360:103-108

Schofield G, Lilley MKS, Bishop CM, Brown P and others (2009) Conservation hotspots: implications of intense spatial area use by breeding male and female loggerheads at the Mediterranean's largest rookery. Endang Species Res 10:191-202

Speed CW, Meekan MG, Bradshaw CJA (2007) Spot the match - wildlife photo-identification using information theory. Front Zool 4:1-11

Editorial responsibility: Paolo Casale, Rome, Italy
Stevick PT, Palsbøll PJ, Smith TD, Bravington MV, Hammond PS (2001) Errors in identification using natural markings: rates, sources, and effects on capture-recapture estimates of abundance. Can J Fish Aquat Sci 58: 1861-1870

Thompson PM, Wilson B, Grellier K, Hammond PS (2000) Combining power analysis and population viability analysis to compare traditional and precautionary approaches to conservation of coastal cetaceans. Conserv Biol 14:1253-1263

Troëng S, Evans DR, Harrison E, Lagueux CJ (2005) Migration of green turtles Chelonia mydas from Tortuguero, Costa Rica. Mar Biol 148:435-447

Troëng S, Solano R, Díaz-Merry A, Ordoñez J and others (2006) Report on long-term transmitter harness retention by a leatherback turtle. Mar Turtle Newsl 111:6-7

van Dam RP, Diez CE (1997) Diving behavior of immature hawksbill turtles (Eretmochelys imbricata) in a Caribbean reef habitat. Coral Reefs 16:133-138

> van Dam RP, Diez CE, Balazs GH, Colón Colón LA, McMillan WO, Schroeder B (2008) Sex-specific migration patterns of hawksbill turtles breeding at Mona Island, Puerto Rico. Endang Species Res 4:85-94

van de Merwe JP (2009) Persistent organic pollutants and heavy metals in the green sea turtle, Chelonia mydas. PhD thesis, Griffith University, Brisbane

van Tienhoven AM, Den Hartog JE, Reijns RA, Peddemors VM (2007) A computer-aided program for pattern-matching of natural marks on the spotted raggedtooth shark Carcharias taurus. J Appl Ecol 44: 273-280

Verner J, Breese D, Purcell KL (2000) Return rates of banded grainivores in relation to band color and number of bands worn. J Field Ornithol 71:117-125

> Zimmerman GS, Kendall WL, Moser TJ, White GC, Doherty PF Jr (2009) Temporal patterns of apparent leg band retention in North American geese. J Wildl Manag 73: 82-88

Submitted: January 14, 2014; Accepted: July 17, 2014 Proofs received from author(s): October 21, 2014 